\title{
Myelinated fibres in the human paravertebral sympathetic chain; quantitative studies on white rami communicantes
}

\author{
OTTO APPENZELLER AND GARY OGIN \\ From the Department of Neurology, The University of New Mexico School of Medicine, \\ Albuquerque, New Mexico 87106, U.S.A.
}

SUMMARY Myelinated fibres in the human sympathetic paravertebral chain were examined histologically and in single teased fibre preparations in various age groups in subjects dying from disorders not affecting primarily the autonomic nervous system. An increase in fibre density predominantly due to an increase in the number of small fibres was found in older subjects. A correlation between internodal length and fibre diameter was found but the internodes of sympathetic myelinated fibres are shorter for any given diameter than those found on fibres of comparable size in the sural nerve. A reduction in internodal lengths with advancing years was demonstrated. These observations are interpreted to show that Wallerian degeneration and segmental demyelination occur with increasing frequency in old age and that regeneration does not keep pace with successive degenerative events. The deterioration in function of the autonomic nervous system with advancing years may be attributed in part to the changes found in myelinated fibres in the paravertebral sympathetic chain.

A deterioration of function with age has been demonstrated clinically in the peripheral nervous system (Critchley, 1931; Howell, 1949). Thus, a decrease or loss of ankle jerks and diminution of vibration sense are common findings in the elderly. Nerve conduction velocities are also slower in late life (Norris, Shock, and Wagman, 1953). The morphological basis for this functional deterioration with age in peripheral nerves has now been clarified. In the sural nerve, for example, irregularities of internodal lengths are rare under the age of 65 years but are found with increasing frequency in older subjects. These irregularities appear to be the result of both Wallerian degeneration and of segmental demyelination and remyelination. Because regeneration does not keep pace with successive degenerative events, a reduction of myelinated fibre population occurs with advancing years (O'Sullivan and Swallow, 1968; Ochoa and Mair, 1969). The clinical and electrophysiological findings in old age could well be accounted for by the morphological aspects of ageing in peripheral nerves. The non-uniform involvement of fibres with age leads to temporal dispersion of impulses and, as in demyelinating peripheral neuropathies, results in the loss of ankle jerks and vibration sense; both of these functions seem to depend on the ability of the nerve to transmit synchronous impulses. The cause of degenerative findings in aged peripheral nerves has not been identified. Ischaemia due to occlusion of vasa nervorum or cumulative effects of repeated minor trauma have, however, been suggested as possibly of aetiological importance.

Autonomic function has also been shown to deteriorate with advancing years (Appenzeller and Descarries, 1964; Gross, 1970). The morphological correlates of this functional deterioration with age have not been sought, though some degenerative changes in sympathetic ganglia are found more frequently in the elderly (Appenzeller and Richardson, 1966). Quantitative studies of normal and pathological peripheral nerves have proved useful in explaining the clinical changes accompanying age. Similar studies on myelinated 
fibres of the human paravertebral sympathetic chain are reported in this paper.

Preganglionic myelinated fibres from the intermediolateral cell column enter the anterior nerve roots between $T_{1}$ and $L_{2}$ and some leave the roots as white rami communicantes. They reach the sympathetic paravertebral chain and course up and down the chain or through it before synapsing on neurones and on viscera or within the ganglia. These are the myelinated fibres found within the paravertebral sympathetic chain which were examined in this study.

\section{METHODS}

The paravertebral sympathetic chain was taken at necropsy from subjects without clinical evidence of autonomic dysfunction. The age, sex, and cause of death in each case are shown in Table 1 . A specimen measuring 5 to $7 \mathrm{~cm}$ in length and including the

TABLE 1

SUBJECTS STUDIED

\begin{tabular}{|c|c|c|c|}
\hline $\begin{array}{c}\text { Case } \\
\text { no. }\end{array}$ & $\begin{array}{l}\text { Age } \\
(y r)\end{array}$ & Sex & Diagnosis \\
\hline $\begin{array}{r}1 \\
2 \\
3 \\
4 \\
5 \\
6 \\
7 \\
8 \\
9 \\
10 \\
11 \\
12 \\
13 \\
14 \\
15 \\
16 \\
17 \\
18 \\
19 \\
20 \\
21 \\
22 \\
23 \\
24 \\
25 \\
26 \\
27 \\
28 \\
29 \\
30\end{array}$ & $\begin{array}{r}0 \\
0 \\
0 \\
0 \\
0 \\
0 \\
3 \\
5 \\
19 \\
23 \\
44 \\
48 \\
48 \\
49 \\
57 \\
60 \\
60 \\
61 \\
62 \\
63 \\
68 \\
68 \\
69 \\
70 \\
72 \\
74 \\
77 \\
81 \\
83 \\
96\end{array}$ & $\begin{array}{l}\mathbf{F} \\
\mathbf{F} \\
\mathbf{M} \\
\mathbf{M} \\
\mathbf{M} \\
\mathbf{F} \\
\mathbf{F} \\
\mathbf{M} \\
\mathbf{F} \\
\mathbf{M} \\
\mathbf{F} \\
\mathbf{F} \\
\mathbf{F} \\
\mathbf{M} \\
\mathbf{M} \\
\mathbf{M} \\
\mathbf{F} \\
\mathbf{M} \\
\mathbf{M} \\
\mathbf{F} \\
\mathbf{M} \\
\mathbf{F} \\
\mathbf{F} \\
\mathbf{M} \\
\mathbf{F} \\
\mathbf{F} \\
\mathbf{F}\end{array}$ & $\begin{array}{l}10 \text { w. gestation } \\
12 \text { w. gestation } \\
16 \text { w. gestation } \\
\text { Stillborn } 7 \frac{1}{2} \text { m. gestation } \\
\text { Stillborn full term } \\
\text { Full term, survived } 36 \mathrm{hr} \\
\text { Spinal cord tumour with } x \text {-radiation to spine } \\
\text { Congenital heart disease } \\
\text { Mental retardation } \\
\text { Brain-stem glioma; postoperative death } \\
\text { Head trauma } \\
\text { Cancer of cervix; postoperative haemorrhage } \\
\text { Idiopathic thrombocytopenic purpura } \\
\text { Cancer of oesophagus } \\
\text { Myocardial infarction } \\
\text { Pulmonary emboli; dementia } \\
\text { Carcinoma of bladder } \\
\text { Perforated gastric ulcer } \\
\text { Acute myocardial infarction } \\
\text { Polymyositis } \\
\text { Renal cell carcinoma } \\
\text { Renal failure without neuropathy } \\
\text { Alzheimer's disease } \\
\text { Gastrectomy, surgical death } \\
\text { Subhepatic abscess after gastric surgery } \\
\text { Intestinal obstruction } \\
\text { Brain-stem haemorrhage } \\
\text { Intracerebral haemorrhage } \\
\text { Fracture of femur; pulmonary embolism } \\
\text { Arteriosclerosis }\end{array}$ \\
\hline
\end{tabular}

third to the fifth thoracic ganglia was gently stretched over a small piece of cardboard and dried for a few minutes in air before immersion in $10 \%$ formolsaline. Post-fixation was carried out in $1 \%$ osmium tetroxide for 24 hours. After fixation, an interganglionic segment of the paravertebral sympathetic chain was dissected. The tissue was embedded in paraffin and sectioned at $4 \mu \mathrm{m}$.

The sections were dehydrated, cleared, and mounted in Canada balsam. Cross-sections were photographed at a magnification of $\times 10.5$ for an over view. Photographs of representative areas of the cross sections were also taken at a magnification of $\times 258$. Kodak Panatomic film developed in D-76 developer was used. Fibre diameter spectra were made after projecting the negative onto an aluminium screen through a Kodak film strip projector at a final magnification of $\times 8,920$. A planimeter was used for measurement of fascicular area of the projected image at a final magnification of $\times 121$.

Internodal length was measured on single fibres teased from interganglionic tissue. The formalin fixed samples were post-osmicated in $1 \%$ osmium tetroxide solution for 24 hours. The tissue was then washed in several changes of distilled water, buffered at $\mathrm{pH} 1 \cdot 5-2$, and slit lengthwise into finer pieces. Samples were incubated in buffered $0.05 \%$ pepsin solution at $37^{\circ} \mathrm{C}$ for two to three weeks with solution changes at 24 hour intervals. After some days of incubation with pepsin, the digestion of the tissue was aided by gentle teasing of bundles under a dis secting microscope to separate the digested area $\$$ and facilitate penetration of the enzyme. Enzyme activity was allowed to continue until fibres separo ated readily. The tissue was then washed in distilled water and soaked in $70 \%$ glycerin-ethanol solution for 24 hours. Single fibres were then separated in glycerin, and transferred to glass slides for mounting? in Canada balsam. Technical problems limited the number of fibres obtained from a single specimen to approximately 15 . Measurements of internodal lengths were made at a magnification of $\times 430$ and of fibre diameter at a magnification of $\times 880$. Five measurements of diameter were made along each internode, the mean of these readings being taken as the diameter of the internode. The measurements obtained with this method were checked on the same tissue in two subjects using preparations of single teased fibres obtained by the methods described by Vizoso and Young (1948) and by Thomas and Young (1949). Comparison of internodal lengths obtained by the two methods on fibres of comparable size showed no statistically significant differences.

\section{RESULTS}

The arrangement of myelinated fibres in interganglionic segments of the human paravertebral sympathetic chain is illustrated in Fig. 1. A predominantly marginal distribution of fibres was found. Islands of myelinated fibres occur inter- 


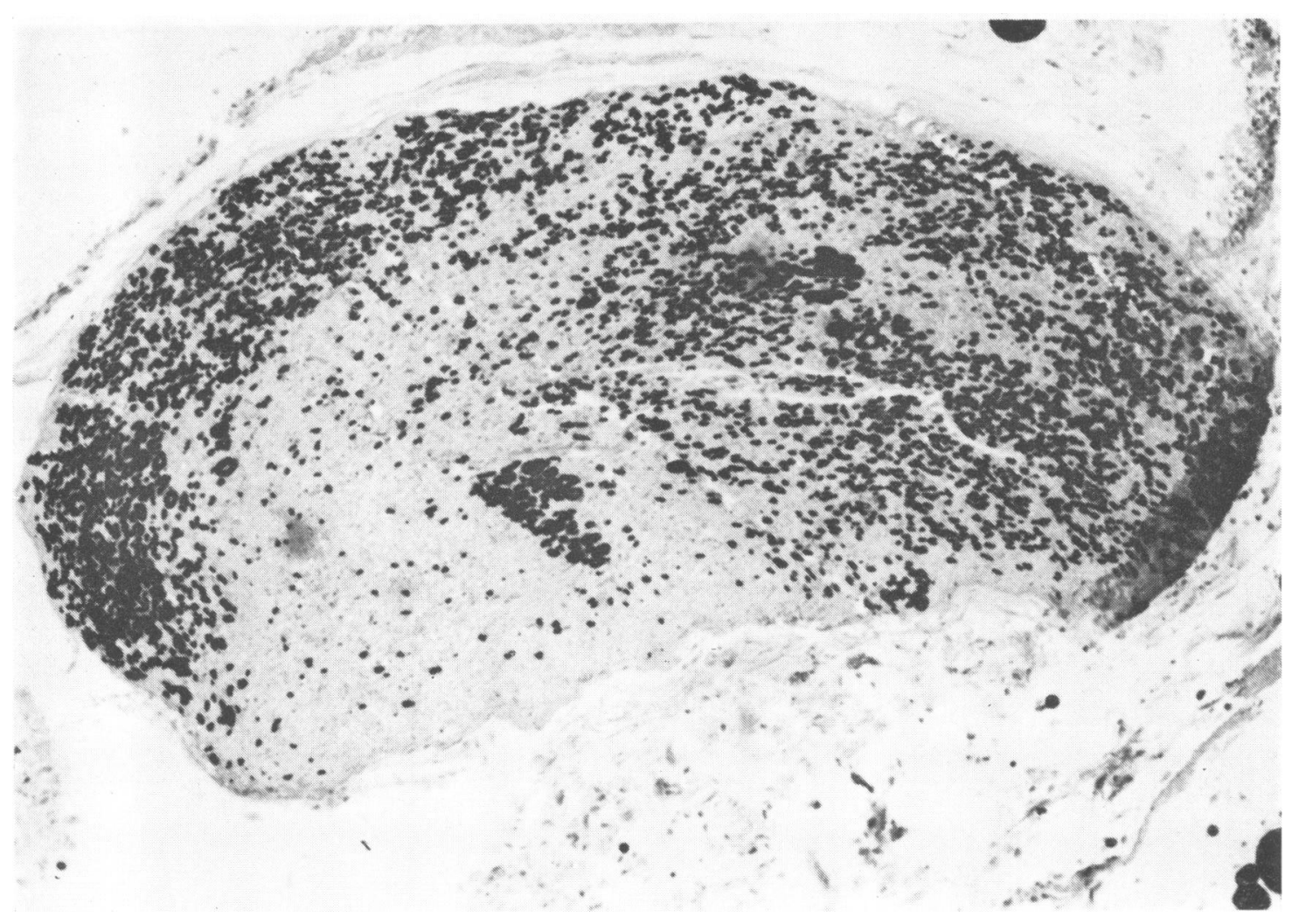

FIG. 1. Myelinated fibres in human interganglionic paravertebral sympathetic segment. Overview showing predominantly marginal distribution of fibres. Osmium tetroxide, $\times 150$.

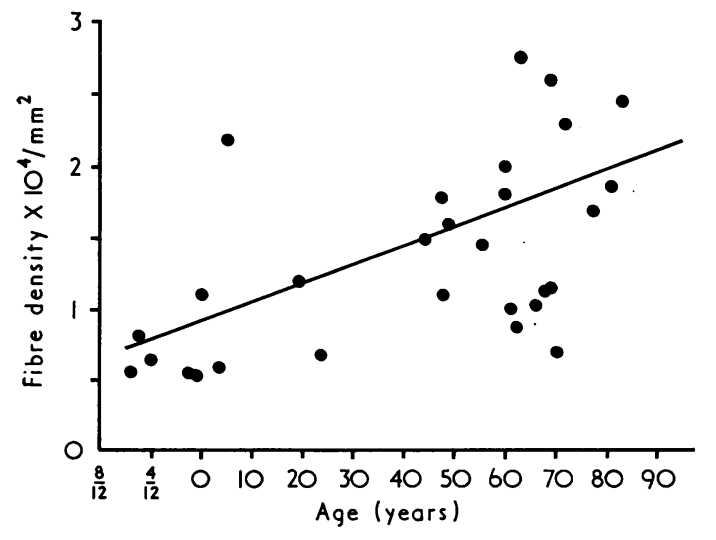

FIG. 2. Myelinated fibre density plotted against age. The calculated regression line is also shown. spersed throughout the rest of the tissue. Some segments are entirely composed of small fibres; others show a predominance of large fibres; some areas are made up of a mixture of both large and small myelinated fibres.

The fascicular area of interganglionic segments showed considerable variation. It varied from $0 \cdot 1$ square $\mathrm{mm}$ (case 29) to 2.4 square $\mathrm{mm}$ (case 13). There was no correlation between the fascicular area and the age of the subjects.

The fibre densities expressed as the number of fibres per square $\mathrm{mm}$ of intraperineural area varied markedly. Densities ranged from 5,300 per square $\mathrm{mm}$ (case 4 ) to 24,500 per square $\mathrm{mm}$ (case 29). An increasing fibre density with advancing years was found. Though this relationship was statistically not significant, a suggestive positive correlation is evident from the calculated regression line (Fig. 2). 
FIG. 3. Myelinated fibre diameter spectra (four subjects) from the paravertebral sympathetic interganglionic segment.

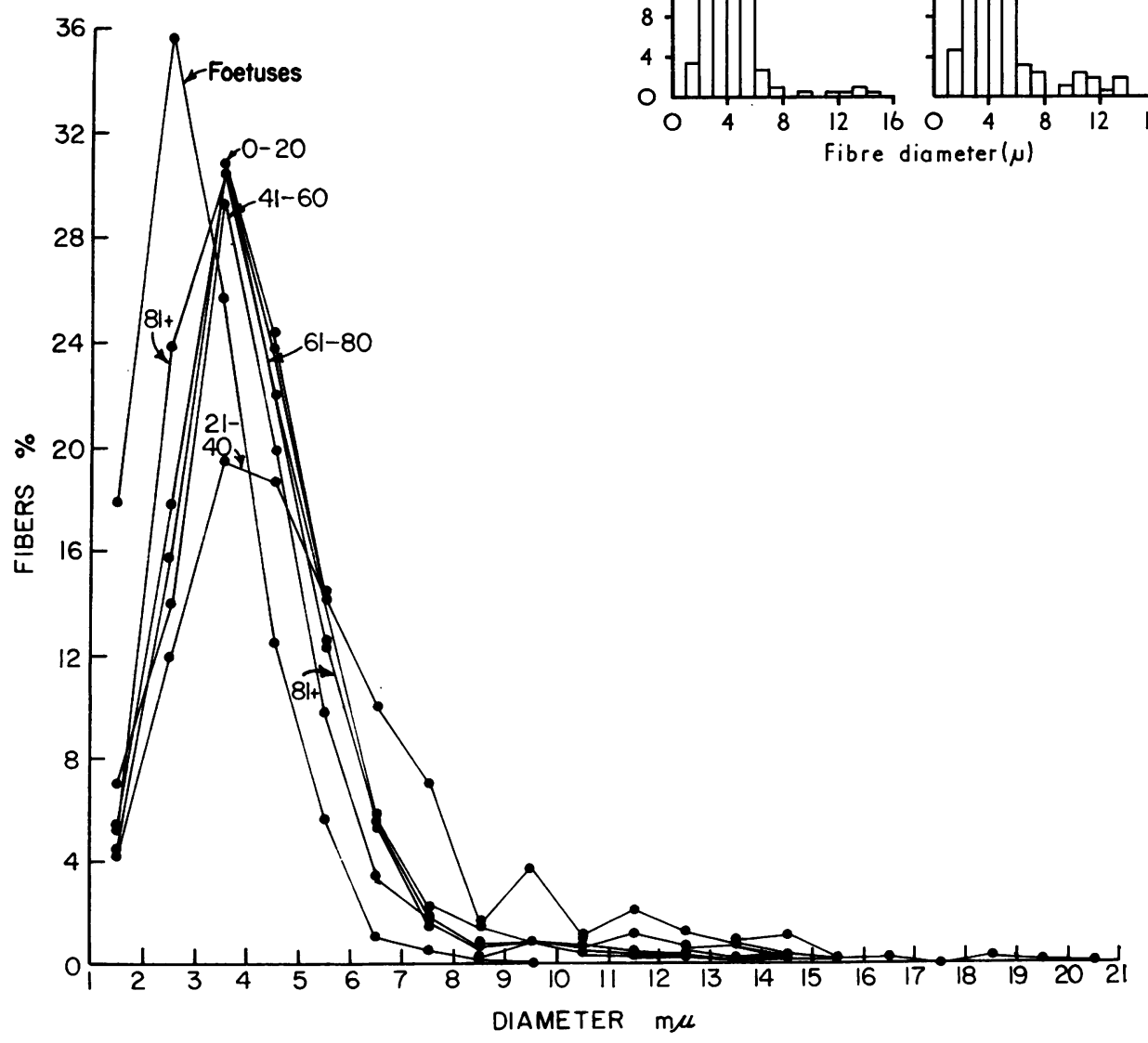

FIG. 4. Myelinated fibre diameter spectra. All subjects, average for age groups. 

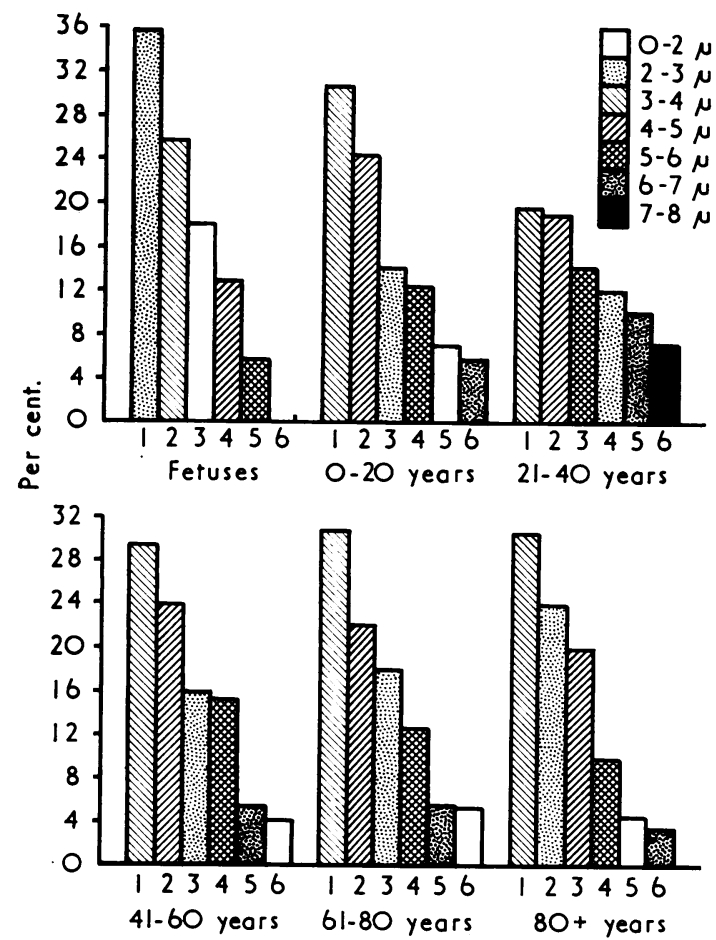

FIG. 5. Rank order of fibre size. All subjects, average for age groups.

The fibre size distribution of representative subjects is shown in Fig. 3 and the average fibre size spectrum for all subjects in Fig. 4. A definite shift to the right in the size of the commonest fibres occurs after birth. The rank order of fibre diameters in various age groups is illustrated in Fig. 5. An increase in the percentage of fibres of less than $3 \mu \mathrm{m}$ in diameter can be seen after the age

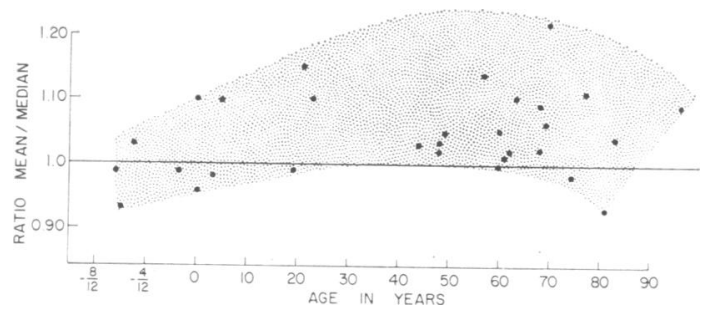

FIG. 6. Ratio of mean/median diameter of myelinated fibres. The larger the ratio the greater the variability of fibre sizes. Stippled area=hypothetical range of normal.
TABLE 2

REGRESSION COEFFICIENTS FOR NERVES EXAMINED

\begin{tabular}{|c|c|c|c|c|c|c|}
\hline $\begin{array}{l}\text { Case } \\
\text { no. }\end{array}$ & $\begin{array}{l}\text { Age } \\
(y r)\end{array}$ & $n$ & $a_{0}$ & $a_{1}$ & $o$ & Comments \\
\hline 7 & 3 & 92 & $123 \cdot 9$ & $3 \cdot 6$ & $62 \cdot 8$ & $\begin{array}{l}\text { Spinal cord tumour } \\
\text { radiation to spine }\end{array}$ \\
\hline 10 & 23 & 106 & $-8 \cdot 4$ & $19 \cdot 8$ & $53 \cdot 3$ & Brain-stem glioma \\
\hline 12 & 48 & 44 & $35 \cdot 0$ & $29 \cdot 0$ & $61 \cdot 0$ & Cancer of cervix \\
\hline 16 & 60 & 144 & $13 \cdot 0$ & $18 \cdot 3$ & $53 \cdot 9$ & Pulmonary embolus \\
\hline 20 & 63 & 46 & $59 \cdot 8$ & $15 \cdot 3$ & $58 \cdot 3$ & Polymyositis \\
\hline 26 & 74 & 34 & $36 \cdot 7$ & $15 \cdot 0$ & $37 \cdot 9$ & Intestinal obstruction \\
\hline 28 & 81 & 116 & $25 \cdot 5$ & $26 \cdot 4$ & $93 \cdot 1$ & Intracerebral haemorrhage \\
\hline
\end{tabular}

$\mathbf{n}=$ Number of internodes examined

$a_{0}=y$ axis intercepts.

$a_{1}=$ regression coefficients.

$\mathrm{o}=$ standard deviation about regression line.

of 40 years. The variability in fibre sizes at various ages in illustrated in Fig. 6. This shows the ratio of mean fibre size against the median plotted against age. The larger the ratio, the greater the variability of fibre size. The greatest variation in fibre sizes is found between the ages of 40 and 70 years. More uniform fibre sizes occur at the extremes of life.

A correlation between internodal length and fibre diameter was demonstrated at all ages. An example is shown in Fig. 7. Table 2 gives data on the number of internodes measured and the regression coefficients. Case 7 shows extremely short internodes for any given fibre size. This was presumably the result of radiation given to the region of the spinal column and may reflect regeneration of fibres which had undergone Wallerian degeneration (Fullerton et al., 1965; Thomas and Lascelles, 1965). Autonomic function was not tested in this case. Death was due to respiratory failure. Figure 8 shows the calculated regression lines for internodal length and fibre diameter for control subjects and also gives a comparison of the regression lines when the $y$-axis intercepts have been reduced to zero. The mean regression lines of subjects older or younger than 60 years of age are shown in Fig. 9. A reduction in internodal length with advancing years is shown by the reduced slope of the older subjects.

It has been shown that fibres that regenerated after Wallerian degeneration showed uniformly short internodes for fibre size and those that had undergone segmental demyelination and remyelination showed internodes of normal and 


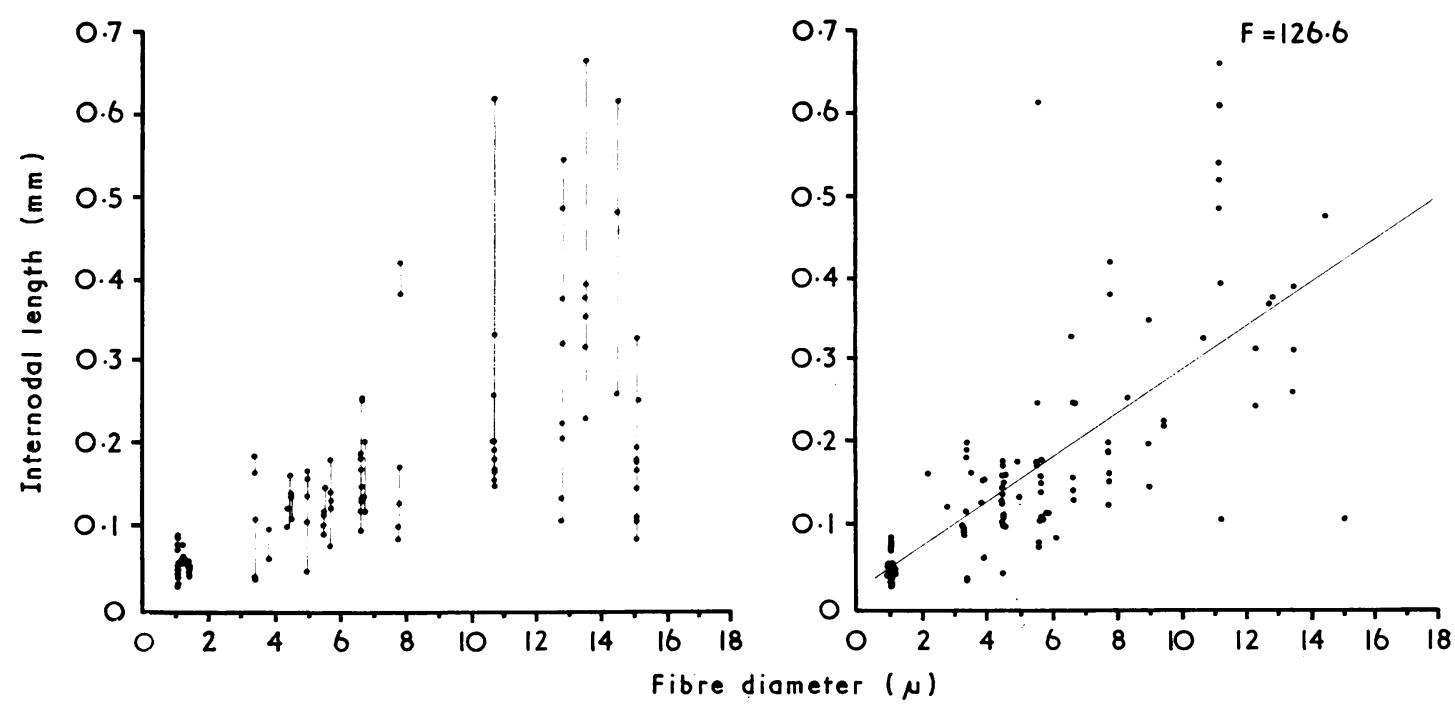

FIG. 7. Aged 81 years. Relationship between internodal length and fibre diameter. Internodal length of individual fibres plotted against widest diameter of fibre and joined by a line (left). Calculated regression line shows statistically significant correlation between internodal length and fibre diameter (right).
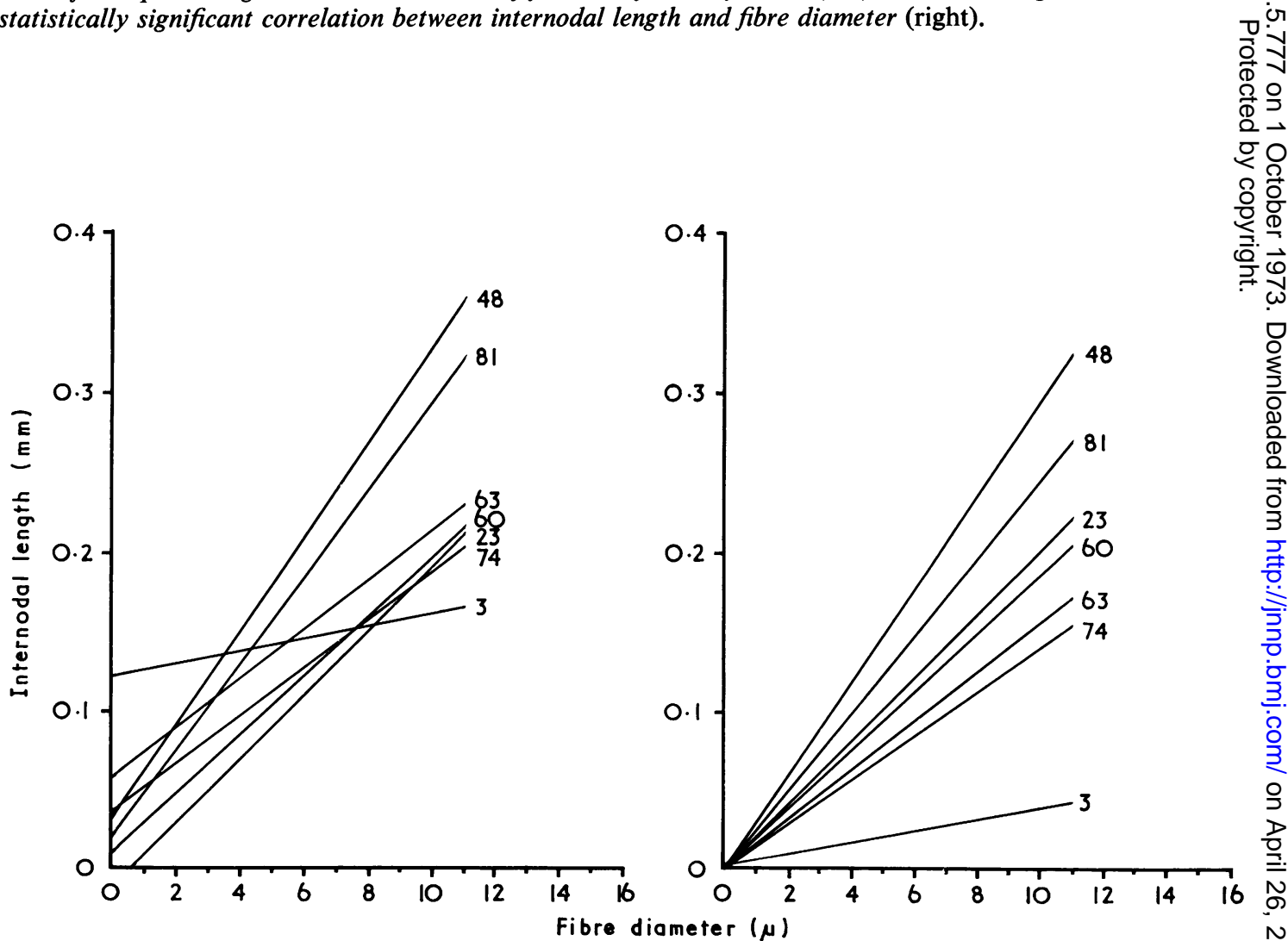

FIG. 8. Calculated regression lines showing relationship between internodal length and fibre diameter (left). Regression lines with y-axis intercepts reduced to $O$ (right). The numbers correspond to the age of the subjects. 


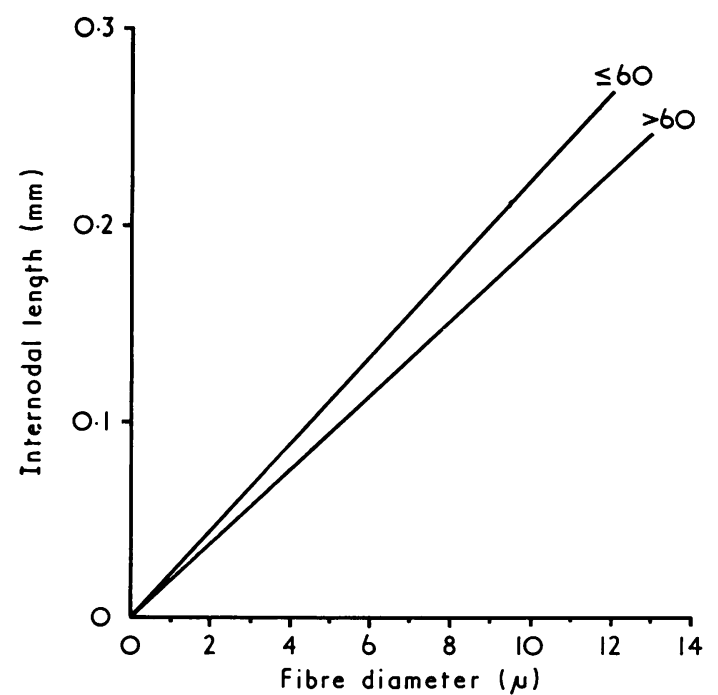

FIG. 9. Relationship between internodal length and fibre diameter. Mean regression lines for subjects younger and older than age 60. The reduction in slope of older subjects indicates shorter internodes.

reduced lengths (Fullerton et al., 1965; Thomas and Lascelles, 1965). Figure 7 shows that both uniformly short internodes and internodes of varying length can be found on any one fibre, particularly in older subjects. This suggests that both Wallerian degeneration and segmental demyelination and remyelination had occurred in the paravertebral sympathetic chain.

A feature of white rami communicantes is the extreme shortness of internodes. They are only approximately one-third in length when compared with values for internodal length reported for sural nerve fibres (Lascelles and Thomas, 1966).

\section{DISCUSSION}

Comparison of biometric data for myelinated fibres given in this report with those for the sural nerve should be interpreted with caution. Nevertheless, these are the only data for comparison available in man.

While variation of fibre size spectrum in various fascicles of the sural nerve occurs, this variability is never as pronounced as that described for myelinated fibres in interganglionic segments of the paravertebral sympathetic chain. In this tissue, whole portions of the fascicle appear devoid of myelinated fibres which are predominantly situated in the periphery.

The values given for fibre density may be affected by changes in fascicular area and also by the number of fibres. In the sural nerve, a decrease in fibre density with advancing age but constant values for fascicular areas were found (O'Sullivan and Swallow, 1968). The paravertebral sympathetic chain shows no significant trend in fascicular area but an increasing density of fibres with advancing years. A full explanation for these findings must await further study. However, an examination of the rank order of fibre sizes at various ages shows that the percentage of smaller fibres (less than $3 \mu \mathrm{m}$ ) increases after the age of 40 years. This suggests that degeneration and regeneration is continuing throughout later life and the percentage increase in small myelinated fibres could be the result of axonal sprouting. This could also account for the increasing density of myelinated fibres in the paravertebral sympathetic chain after the age of 40 years. The fibre density in interganglionic segments is higher than that reported for the sural nerve where the upper limit was found to be 8.99 thousand fibres/sq. mm compared with 24,500 myelinated fibres/sq. $\mathrm{mm}$ in the sympathetic chain. The high density of fibres found in the upper part of the chain in this study may not, however, be present distally, since fibre branching may profoundly affect fibre density at different levels.

The evolution of the shape of the size frequency histogram with age shows that, in the sympathetic chain, there is no change from a unimodal to bimodal distribution of myelinated fibre sizes at birth such as occurs in the sural nerve (Ochoa, 1971). A suggestion of bimodality of sympathetic myelinated fibre size is, however, found after the age of 20 years. Axons continue to grow after the formation of myelin and longitudinal growth leads to elongation of myelin segments (internodes) without, apparently, the addition of further segments (Boycott, 1904; Young, 1945; Thomas and Young, 1949). Growth in diameter has also been demonstrated and axons which myelinate first apparently attain the largest final diameter (Boughton, 1906). The shift to the right in the size frequency 
distribution of fibre diameters after birth in the sympathetic chain must be attributed to the growth in the diameter of fibres that myelinated early. The increase in fibre density after birth shown in the present study may be explicable also by the finding of McKinniss (1936) who showed that dorsal root ganglion cells increase in number during the development of the human fetus. Whether a similar increase in the number of cells in the intermediolateral and intermediomedial cell columns of the spinal cord occurs during development to account for the increasing fibre density has not been established.

Dissection of single myelinated axons from peripheral nerves has been practised since the days of Gombault (1880). He demonstrated segmental demyelination in lead poisoning and his technical excellence has rarely been equalled. Recently, this technique has been used again. Segmental demyelination in peripheral nerve disease associated with diabetes (Thomas and Lascelles, 1966), diphtheria (Cavanagh and Jacobs, 1964), peroneal muscular atrophy (Gutrecht and Dyck, 1966), and chronic uraemia (Appenzeller et al., 1971) has been demonstrated. The incidence of abnormalities in single axon dissections in so-called 'normal' human peripheral nerves in various age groups has also been studied (Arnold and Harriman, 1970). This technique is ideal for the demonstration of segmental demyelination which otherwise can only be seen imperfectly in sectioned material and may remain unrecognized. Segmental demyelination of sympathetic myelinated fibres was found in several segments from older subjects and successive remyelination was demonstrated by the presence of internodes of different lengths on many fibres.

Though in adult peripheral mammalian nerves, including man, the relationship between internodal length and fibre diameter is approximately linear, a number of irregularities of internodal length occur and these become more frequent with advancing years. Abnormally short internodes for a given diameter of fibre are attributed to segmental demyelination and remyelination or result from complete degeneration of fibres followed by regeneration (Vizoso, 1950). In the sural nerve, internodal length varies from approximately $0.15 \mathrm{~mm}$ for fibres with a diameter of $2 \mu \mathrm{m}$ to $1-1 \cdot 12 \mathrm{~mm}$ for fibres with a diameter of $12 \mu \mathrm{m}$. Some internodes as long as $1.3 \mathrm{~mm}$ are occasionally found (Lascelles and Thomas, 1966). In the interganglionic segments of the human paravertebral chain corresponding figures are $0.1-0.15 \mathrm{~mm}$ for fibres $2 \mu \mathrm{m}$ in diameter to approximately $0.7-0.8 \mathrm{~mm}$ for fibres $12 \mu \mathrm{m}$ in diameter. No internodes of the length reported for sural nerves have been found in the interganglionic segments of the sympathetic chain. On the whole, internodes in the sympathetic chain are about one-third shorter when compared with the length of internodes on comparable sized fibres in the sural nerve. The short internodal lengths could be reflected in slow conduction velocities. To our knowledge, however, the conduction in myelinated fibres in human paravertebral sympathetic chain has not been measured. Conduction velocities of $1.2 \mathrm{~m} / \mathrm{sec}$ have been found in the cervical sympathetic chain of the rat (Sacchi and Perri, 1969). The relationship between the diameter of the fibre and its internodal length has been measured for the bullfrog sciatic nerve and found to be expressed by the formula $\mathrm{L}=0.146 \times 10^{3} \mathrm{D}$, where $\mathrm{L}$ is the internodal length and $\mathrm{D}$, the diameter. The relationship be tween the conduction velocity, $\mathrm{V}$, expressed in metres per second, and the diameter (in $\mu \mathrm{m}$ ) has been found to be $\mathrm{V}=2 \cdot 50 \mathrm{D}$. Using these two formulae, the average conduction time for one internode can be expressed by the ratio $\mathrm{L} / \mathrm{V}$ and this equals in the bullfrog sciatic nerve 0.059 $\mathrm{m} / \mathrm{sec}$. Statistically, therefore, the internodal conduction is relatively independent of the fibre diameter (Tasaki, 1959). Using these data and the internodal length found in our own measurements, the ratio $\mathrm{L} / \mathrm{V}$ equals $0 \cdot 190 \mathrm{~m} / \mathrm{sec}$ for a human sympathetic chain internode, or about one-third that of peripheral nerves. This value fits well with the length of the internodes found in the sympathethic interganglionic segments of man. Irregularities in internodal length are commoner in old age as in the sural nerve (Vizoso, 1950). Uniformly short internodes were encountered in the patient receiving radiation to the spinal cord (case 7). This suggested that Wallerian degeneration and regeneration of white rami communicantes in this patient occurred between radiation therapy and death seven months later.

The present observations might contribute to 
the understanding of the deterioration in autonomic function with advancing years (Appenzeller and Descarries, 1964; Gross, 1970). For example, the irregularities in internodal lengths and the general shortening of internodes in old age might be interpreted to show that regeneration does not keep pace with successive degenerative events and the non-uniform involvement of fibres with age leads to temporal dispersion of impulses resulting in an impaired ability of the nerves to transmit synchronous volleys which might be important for baroreflex activity. The progressive loss of larger fibres and increase in the number of smaller fibres presumably reflects collateral sprouting which would have a similar effect on conduction in the paravertebral sympathetic chain.

\section{REFERENCES}

Appenzeller, O., and Descarries, L. (1964). Circulatory reflexes in patients with cerebrovascular disease. New England Journal of Medicine, 271, 820-823.

Appenzeller, O., Kornfeld, M., and MacGee, J. (1971). Neuropathy in chronic renal disease. A microscopic, ultrastructural, and biochemical study of sural nerve biopsies. Archives of Neurology, 24, 449-461.

Appenzeller, O., and Richardson, E. P., Jr. (1966). The sympathetic chain in patients with diabetic and alcoholic polyneuropathy. Neurology (Minneap.), 16, 1205-1209.

Arnold, N., and Harriman, D. G. F. (1970). The incidence of abnormality in control human peripheral nerves studied by single axon dissection. Journal of Neurology, Neurosurgery, and Psychiatry, 33, 55-61.

Boughton, T. H. (1906). The increase in the number and size of the medullated fibers in the oculomotor nerve of the white rat and of the cat at different ages. Journal of Comparative Neurology, 16, 153-165.

Boycott, A. E. (1904). On the number of nodes of Ranvier in different stages of the growth of nerve fibres in the frog. Journal of Physiology, 30, 370-380.

Cavanagh, J. B., and Jacobs, J. M. (1964). Some quantitative aspects of diphtheritic neuropathy. British Journal of Experimental Pathology, 45, 309-322.

Critchley, M. (1931). The neurology of old age. 2. Clinical manifestations in old age. Lancet, 1, 1221-1230.

Fullerton, P. M., Gilliatt, R. W., Lascelles, R. G., and Morgan-Hughes, J. A. (1965). The relation between fibre diameter and internodal length in chronic neuropathy. Journal of Physiology, 178, 26-28P.
Gombault, A. (1880). Contribution à l'étude anatomique de la névrite parenchymateuse subaiguë et chronique. Névrite segmentaire péri-axile. Archives de Neurologie, 1, 11-38.

Gross, M. (1970). The effect of posture on subjects with cerebrovascular disease. Quarterly Journal of Medicine, 39, 485-491.

Gutrecht, J. A., and Dyck, P. J. (1966). Segmental demyelinization in peroneal muscular atrophy: nerve fibers teased from sural nerve biopsy specimens. Mayo Clinic Proceedings, 41, 775-777.

Howell, T. H. (1949). Senile deterioration of the central nervous system. British Medical Journal, 1, 56-58.

Lascelles, R. G., and Thomas, P. K. (1966). Changes due to age in internodal length in the sural nerve in man. Journal of Neurology, Neurosurgery, and Psychiatry, 29, 40-44.

McKinniss, M. E. (1936). The number of ganglion cells in the dorsal root ganglia of the second and third cervical nerves in human fetuses of various ages. Anatomical Record, 65, 255-259.

Norris, A. H., Shock, N. W., and Wagman, I. H. (1953). Age changes in the maximum conduction velocity of motor fibers of human ulnar nerves. Journal of Applied Physiology, 5, 589-593.

Ochoa, J. (1971). The sural nerve of the human foetus: electron microscope observations and counts of axons. Journal of Anatomy, 108, 231-245.

Ochoa, J., and Mair, W. G. P. (1969). The normal sural nerve in man. II. Changes in the axons and Schwann cells due to ageing. Acta Neuropathologia, 13, 217-239.

O'Sullivan, D. J., and Swallow, M. (1968). The fibre size and content of the radial and sural nerves. Journal of Neurology, Neurosurgery, and Psychiatry, 31, 464-470.

Sacchi, O., and Perri, V. (1969). Effetti della piritiamina e dell'ossitiamina sull'ampiezza del potenziale d'azione e la velocità di conduzione delle fibre del tronco simpatico cervicale del ratto. Bollettino della Società Italiana di Biologia Sperimentale, 45, 1597-1601.

Tasaki, I. (1959). Conduction of the nerve impulse. In Handbook of Physiology, Section I. Neurophysiology. Vol. I, pp. 75-121. American Physiological Society: Washington, D.C.

Thomas, P. K., and Lascelles, R. G. (1966). The pathology of diabetic neuropathy. Quarterly Journal of Medicine, 35, 489-509.

Thomas, P. K., and Lascelles, R. G. (1965). Schwann-cell abnormalities in diabetic neuropathy. Lancet, 1, 1355-1357.

Thomas, P. K., and Young, J. Z. (1949). Internode lengths in the nerves of fishes. Journal of Anatomy, 83, 336-350.

Vizoso, A. D. (1950). The relationship between internodal length and growth in human nerves. Journal of Anatomy, 84, 342-353.

Vizoso, A. D., and Young, J. Z. (1948). Internode length and fibre diameter in developing and regenerating nerves. Journal of Anatomy, 82, 110-134.

Young, J. Z. (1945). History of the shape of a nerve-fibre. In Essays on Growth and Form, pp. 41-94. Edited by W. E. Le Gros Clark, and P. B. Medawar. Clarendon Press: Oxford. 